\title{
Applying Yoga Exercises During Home Quarantine and Its Effect On Negative and Positive Thinking for Students of the Department of Physical Education and Sports Science of Al-Maarif University College
}

\author{
Nawfal Qahtan Mohammed ${ }^{1}$, Yasir Mohammed Hammood*2 \\ 1 Directorate of Education, Anbar Governorate, Iraq \\ 2 Department of Physical Education and Sports Sciences, Al-Maarif University College, Anbar, Iraq \\ * yasiralmohana@gmail.com
}

\begin{abstract}
:
Due of the Corona pandemic (Covied19), individuals in all societies, including the Iraqi society, were subjected to great pressures that caused tension and anxiety to confront this pandemic, with many aspects of life disrupting the person's normal life.This study aims to identify the effect of applying yoga exercises during home quarantine and its effect on negative and positive thinking for students of the Department of Physical Education and Sports Science of Al-Maarif University College, using the experimental approach.In practical terms, the importance of the study appears in light of the conditions witnessed by Iraqi society, due to the Corona pandemic and the consequent abolition of all sports, cultural and scientific activities, disrupting official working hours in universities, schools and all state departments, and declaring a state of emergency throughout the country, which requires the use of All means to overcome them, and among those methods, students practice yoga exercises during home quarantine and take advantage of technological development in communicating with others under quarantine conditions. The study is reached that the application of yoga exercises during home quarantine has a clear effect on reducing negative thinking to the research sample and raising their level of positive thinking.
\end{abstract}

Keywords: Yoga; Exercises; Negative Thinking; Positive Thinking; The Corona Pandemic. 


\section{تطبيق تمرينات اليوغا أثناء الحجر المنزلي وتأثيرها على التفكير السلبي والإبيابي لطلاب قسم التربية البدنية وعلوم الرياضة لكلية المعارف الجامعة

$$
\begin{aligned}
& \text { م.د. نوفل قحطان محمد'، م.م. ياسر محمد حمود"2 } \\
& 1 \text { مديرية تربية الأنبار ، محافظة الانبار، العراق } \\
& 2 \text { قسم التربية البدنية وعلوم الرياضة، كلية المعارف الجامعة، الأنبار، العراق } \\
& \text { *yasiralmohana@gmail.com }
\end{aligned}
$$

بسبب جائحة كورونا (كوفيد 19 ) تعرض الأفراد في المجتمعات كافة بها في ذلك المجتمع العر اقي لضغوط كبيرة تسببت في توتر وقلق لمواجهة هذا الوياء، مع تعطل الكثير من جوانب الحياة الطبيعية للإنسان. تهدف هذه الدراسة إلى التعرف على أثر تطبيق تمارين اليوغا أثناء الحجر المنزلي على التفكير السلبي والإيجابي لدى طلاب قسم التربية البدنية وعلوم الرياضة بكلية المعارف الجامعة باستخدام المنهج التجريبي. تظهر أهمية الدراسة من الناحية العملية في ضوء الظروف التي يشهدها المجتمع العراقي بسبب وباء كورونا وما ترتب على ذلك من إلغاء جميع الأنشطة الرياضية والثقافية والعلمية، وتعطيل العمل في الجحامعات والمدارس كافة، وإعلان حالة الطوارئ في جميع أنحاء البلاد، الأمر الذي يتطلب استخدام جميع الوسائل للتغلب عليها، ومن بين تلك الأساليب ممارسة الطلاب تمارين اليوغا أثناء الحجر المنزلي، والاستفادة من التطور التكنولوجي في التواصل مع الآخرين. وتوصلت الدراسة إلى أن تطبيق تمارين اليوغا أثناء الحجر المنزلي له تأثير واضح في تقليل التفكير

$$
\text { السلبي لدى عينة البحث ورفع مستوى التفكير الإيجابي لديهم. }
$$

الكلهـات المفتاحية : يوغا، تهارين، تفكير سلبي، تفكير إيجابي، جـائحة كورونا. Crossref doi https://doi.org/10.51345/.v31i1.220.g147 


\section{المقدمة}

بسبب جائحة كورونا (Covied19) تعرض الافر اد في المجتمعات كافة ومنها المجتمع العراقي المى ضغوط كبيرة سببت التوتر والقلق لمواجهة تلك الجائحة مع تعطل الكثير من جوانب الحياة في ممارسة الانسان لحياته الطبيعية، وهذه الحالة قد سببت ارتفاع مستوى الضغوط النغسية والعقلية والجممية مع استمرار الكثير من افراد المجتمع بمتابعة الاخبار وهم في الحجر المنزلي عن اعداد المصابين والمتوفين بالفيروس مما قد يسبب اثارًا سلبية على الافراد والصحة وذلك لقلة الخبرة في مواجهة هذه الجائحة فيصبح الانسان في حالة صراع مع استمرار عمليات التفكير بوضعه الراهن والمستقبلي ومن نواحي عديدة كالمعيشة أو الوظيفة أو الطموح، واهدافه التي يسعى الى تحقيقها وهو تحت تأثير الحجر المنزلي والهلع الذي سببته الجائحة، فضلاً عن ذلك فان غلق المدارس والجامعات قد يسبب ارتفاع في مستوى التفكير السلبي لدى الكثير من الطلبة وقد يؤدي الى الاستسلام لحالة الخوف والهلع والذي ينعكس بدوره على كفاءة الجهاز المناعي لديهم. وعلى الرغم من قدرة الانسان على التكيّف والتعلمّ للاستجابة سواء الانفعالية أو الجسمية الا أنها تتطلب استخدام اساليب مختلفة لمو اجهة الضغوط كملمارسة الانشطة المختلفة الرياضية أو البدنية أو الترويجية، ومن هذه الانشطة هي تمارين اليوغا التي تعد وسيلة مهمة لكسر الروتين اليومي، وقد توفر بديل نسبي عن ممارسة الانشطة الرياضية الحركية لطلبة كليات التربية الرياضية اثناء تواجدهم في الدروس العملية تحت الظروف الطبيعية، فاليوغا هي "علم يستهدف إعادة التوازن للإنسان جسدًا وعقلًا وروحًا لكي يثير في الانسان القدرات الكامنة "(1) (1)

وتكمن اهمية البحث من الناحية العملية في معالجته الآثار السلبية كالتوتر والقلق الذي يصيب الافراد نتيجة الحجر المنزلي بسبب جائحة كورونا التي اجتاحت المجتمعات كافة ومنها المجتمع العراقي وما ترتب عليها من قيام الحكومة العراقية بإصدار الأمر الديواني المرقم 55 لسنة 2020 والمتضمن تشكيل لجنة خلية الأزمة برئاسة وزير الصحة والبيئة والتي أصدرت ابتداء من تاريخ 26 شباط 2020 مجموعة قرارات تضمنت بمجملها الغاء جميع النشاطات الرياضية والثقافية والعلمية، وغلق المحلات العامة كدور السينما والمقاهي 
والنوادي والمنتديات الاجتحاعية، وتعطيل الدوام الرسمي في الجامعات والمدارس ودوائر الدولة كافة، ومنع السفر الى باقي الدول التي شهدت تفشي هذا الفيروس، ومن ثم اعلان حالة الطوارئ في عموم البلاد. كما تبدو اهمية الموضوع باعتباره وسيلة من وسائل مواجهة جائحة كورونا في ظل غياب الدعم النفسي والطرق والاساليب من مؤسسات الدولة المختلفة لمو اجهتها، إذ أن ممارسة الافراد لتمرينات اليوغا اثناء الحجر المنزلي من شأنه توجيه تفكيرهم الى الناحية الايجابية، ونظرة الم المستقبل تتصف بالأمل، والاستفادة كذلك من التطور التكنولوجي في التو اصل مع الآخرين.

\section{مشكلة البـحث:}

تتمثل اشكالية البحث بالتساؤل الآتي:

هل هناك تأثير اليجابي لتطبيق تمرينات اليوغا أثناء الحجر المنزلي على التفكير السلبي والايجابي لطلاب قسم التربية البدنية وعلوم الرياضة لكلية المعارف الجامعة ؟

\section{أهداف البـحث:}

- اعداد وتطبيق تمرينات اليوغا لطلاب قسم التربية البدنية وعلوم الرياضة لكلية المعارف الجامعة باستخدام منصة free conference call. - تعريف طلاب قسم التربية البدنية وعلوم الرياضة لكلية المعارف الجامعة بتمرينات اليوغا وفوائدها وشروطها. - - بيان تأثير تطبيق تمرينات اليوغا اثناء الحجر المنزلي على التفكير السلبي والايجابي لطلاب قسم التربية البدنية وعلوم الرياضة لكلية المعارف الجامعة.

\section{فرضية البحث:}

توجد فروق معنوية بين نتائج القياس القبلي والبعدي في التفكير السلبي والايجابي لطلاب قسم التربية البدنية وعلوم الرياضة لكلية المعارف الجامعة. 


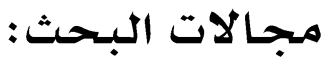

المجال البشري: 30 طالب - قسم التربية البدنية وعلوم الرياضة - كلية المعارف الجامعة . المجال الزماني: للمدة من 15 / 6 / 2020 لغاية 12 / 72020. المجال المكاني: مدينة الرمادي عبر المنصة الالكترونية free conference call.

الدراسـات النظريـة:

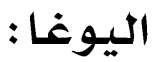

هي من "انواع الممارسات او الرياضات التي توصف بالروحية لأنها تربط ما بين العقل والجسد، ولليوغا انواع متعددة من الوضعيات تجمع بين الاسترخاء او التأمل مع استخدام طريقة معينة من التنفس، وان استخدام نوع اليوغا المناسب يعتمد على الدرجة التي يتمتع بها الجمسم من اللياقة لذا فهي تمثل تعزيز السيطرة للفرد على العقل والجسم للوصول المى الراحة"(2). وهناك عدد من النصائح عند ممارسة اليوغا هي:

" توفير المكان المناسب المريح : غرفة تتصف بالهدوء وفارغة الى حد ما. توفير الادوات اللازمة : مثل الحصيرة خاصة لتجنب الانزلاق او يمكن التعويض عنها بالبطانيات. حماية الجمسم من الاصابة: أن يعرف المتدرب أن الركبتان، الرقبة، الوركان، العمود الفقري، هي من المناطق الحساسة.

نوع اليوغا الملائم : أن يحدد الفرد الفئة الملائمة من التمرينات وذلك بالاستعانة بالمختصين أو الانترنيت. الانتظام في ممارسة اليوغا: لمرة واحدة في الاسبوع يعد ذات فائدة، اما تطبيقها لثلاث مرات تكون اكثر فائدة، وهذا افضل من أن يشعر الفرد بالفشل عند ممارستها يوميًا لكل الاسبوع"(3). 
التفكير:

هو: "نشاط عقلي واعي يعكس فيه الإنسان الواقع الموضوعي بطريقة مختلفة تمامًا عما يحدث في الاحساس والادراك، وهو عملية عقلية معرفية يتم من خلالها انعكاس العلاقات والروابط بين الظاهرات والاشياء في وعي الانسان"(4). (4) - (4)

ويتناقض التفكير السلبي مع الايجابي فالأول فيه يضع الافراد ميولمم نحو توقع الامور السيئة مما يسبب ضغوطًا هائلة تؤدي الى القلق أو الخوف من أشياء قد تكون غير واقعية، اما التفكير الايجابي والذي يرتبط بسمة التفاؤل و الذي يرتكز على التعامل مع كل موقف أو ظرف بشكل بعيد عن حالة التشاؤم.

منهجيـة البـحث واجراءاته الميدانية : منهجية البحث:

استخدم الباحثان المنهج التجريبي بتصميم المجوعة التجريبية الواحدة ذات الاختبار القبلي والبعدي.

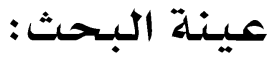

تألفت عينة البحث من 30 طالبًا من المستمرين بالدراسة في قسم التربية البدنية وعلوم الرياضة لكلية المعارف الجامعة، في مدينة الرمادي، محافظة الانبار . إذ تم اختيار 10 طلاب من الذكور من كل مرحلة الأولى والثانية و الثالثة، بطريقة عمدية بعد ابداء رغبتهم والاستعداد للمشاركة في العينة البحثية.

الأجهزة والادوات ووسائل جمع المعلومات: الاجهزة والأدوات:

- حاسوب نوع - حاسبة رقمية. 


\section{وسائل جمع المعلومات:}

- - مادمادر العربية والأجنبية.

- مبكة المعلومات الدولية الانترنيت.

- - الاختبار و القياس.

- المنصة الإلكترونية (free conference call)

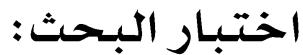

تم اختيار مقياس التفكير السلبي والايجابي المعد من قبل احد محمود (ملحق 1 ) ، "ويتألف المقياس من 60 فقرة ويضم ثلاثة بدائل هي تنطبق عليَّ كثيرًا، تنطبق عليَّ احيانًا، لا تنطبق عليَّ. وتمنح درجات 3| 2 أ 1 على التوالي للفقرات الايجابية وعددها 24 فقرة، وتمنح درجات 1، 2 ، 3 للفقرات السلبية وعددها 36 فقرة، وتكون درجة المقياس تتراوح بين 60-120 درجة وتبلغ درجة المتوسط الفرضي للمقياس 120 درجة" أعلمًا أن المقياس قد تم بناءه بها يتلاءم و البيئة العراقية(5).

\section{إجراءات البحث : - إلبح

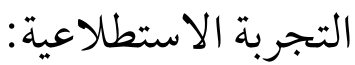

قام الباحثان بأجراء هذه التجربة على أفراد عينة البحث البالغ عددهم 30 طالبًا، و كان الغرض منها شرح طريقة العمل للمنصة الإلكترونية free conference call والتعرف على المعوقات التي تعترض أفراد العينة عند تطبيق التجربة الرئيسية، كما شملت التجربة الرئيسية تزويد المتعلمين بمعلومات معرفية عن تمرينات اليوغا وطريقة اداءها مع الحفاظ على حركات التنفس وتهيئة المكان لأداء التمرينات اثناء الحجر المنزلي وشروطه، وكذلك تزويد افراد العينة بمجموعة من الصور وفيديو يوضح طريقة أداء تمرينات اليوغا المختارة، وقد تم اجر اء هذه التجربة في الساعة العاشرة صباحًا من يوم الخميس بتأريخ 28 / 5 / 2020 


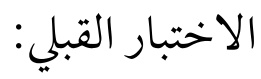

تم إجر اء الاختبار القبلي للإجابة على مقياس التفكير السلبي والايجابي من قبل أفراد عينة البحث عبر المنصة الإلكترونية من خلال برنامج google forms المختارة في الساعة العاشرة صباحًا من يوم السبت بتأريخ $.2020 / 5 / 30$

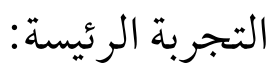

تم إعداد بجموعة من تمرينات اليوغا ويها يتلاءم مع مستوى أفراد عينة البحث وذلك بالاطلاع على المصادر العلمية ومواقع الانترنيت الخاصة بتمرينات اليوغا، إذ يتم عرضها من قبل المنصة الإلكترونية من خلال الصور ومقاطع فديو والتي استغرقت عرض لمدة عشر دقائق باستخدام عرض PowerPoint، ثم يقوم أفراد العينة بتطبيق التمرينات وفق وقت محدد إذ يستغرق كل تمرين وقت من 30 ثانية الى 60 ثانية وحسب قدرة الطالب مع تكرار التمرين 3-4 مرات، ويتم تنفيذ من 6 - 8 تمرينات في كل جلسة مع التدرج في سهولة التمرينات في الاسبوع الأول ثم الاتجاه تدرجيًا المى تمرينات اكثر صعوبة، واستغرق تنفيذ البرنامج مدة شهر بو اقع ثلاث جلسات في الاسبوع، مع التأكيد على الاسترخاء و الراحة بعد كل تمرين. وتم العرض في الساعة العاشرة صباحًا من ايام الاثنين والاربعاء والجمعة.

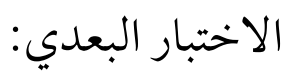

بعد الانتهاء من تطبيق تمرينات اليوغا في التجربة الرئيسة للبحث، تم اجراء الاختبار البعدي للإجابة على مقياس التفكير السلبي والايجابي وعبر المنصة الإلكترونية في نفس الظروف التي تم فيها الاختبار القبلي من يوم الاثنين بتاريخ 13 / 7 / 2020. 


\section{الوسائل الاحصائية : "(T) للعينات المتنـاظرة"(6)}

\section{عرض النتائج وتحليلها ومناقشتها :}

عرض نتائج الاوساط الحسابية والانحرافات المعيارية للاختبار القبلي والبعدي وفرق الاوساط وفرق الانحرافات للتفكير السلبي والاييابي ودلالة الفروق بين نتائج الاختبارين. جدول (1) الجدولية 1.978، تحت مستوى دلالة 0.0 0، ودرجة حرية 30 - 29 =

\begin{tabular}{|c|c|c|c|c|c|c|c|c|c|}
\hline \multirow{2}{*}{ الفروق } & \multirow{2}{*}{$\begin{array}{c}\text { T } \\
\text { المحسوبة }\end{array}$} & \multirow[t]{2}{*}{ ع ف } & \multirow[t]{2}{*}{ سَ ف ف } & \multicolumn{2}{|c|}{ البعدي } & \multicolumn{2}{|c|}{ القبلي } & \multirow{2}{*}{ القياس } & \multirow[t]{2}{*}{ المتغيرات } \\
\hline & & & & $\varepsilon$ & س & $\varepsilon$ & س & & \\
\hline دالة & 7.14 & 1.82 & 1.6 & 0.90 & 1 & 0.68 & 2.6 & درجة & التفكير \\
\hline دالة & 9.77 & 1.02 & 1.76 & 0.75 & 3 & 1.31 & 1.33 & درجة & التفكير \\
\hline & & & & & & & & & \\
\hline
\end{tabular}

\section{تحليل النتائج ومناقشتها :}

وضَّح الجدول (1 ) نتائج الاختبار القبلي والبعدي لقياس التفكير الايجابي والسلبي لأفراد عينة البحث، إذ بلغ الوسط الحسابي القبلي للتفكير السلبي (2.6) وبانحراف معياري (08) 0.6، وفي الاختبار البعدي بلغ الوسط الحسابي (1) ويانحر اف معياري (0.90)، في حين بلغت قيمة فرق الاوساط (1.6) وفرق الانحرافات (1.82)، اما قيمة T المحسوبة بلغت (74.14) وهي اكبر من قيمة T الجلدولية البالغة (1.978) )، ما يؤكد على التأثير الايجابي لتمرينات اليوغا. في حين بلغ الوسط الحسابي القبلي للتفكير الايجابي (1.33) وبانحراف معياري (1.31)، وفي الاختبار البعدي بلغ الوسط الحسابي (3) وبانحراف معياري (0.75)، في حين بلغت قيمة فرق الاوساط (1.76) وفرق الانحرافات (1.02)، اما قيمة T المحسوبة بلغت (9.77) وهي اكبر من قيمة T الجلدولية البالغة

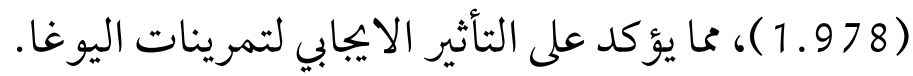


يتضح في جدول (1 ) أن الفرق اثبت نجاح تمرينات اليوغا على رفع مستوى التفكير الايجابي وخفض مستوى التفكير السلبي لدى افراد عينة البحث في نتائج الاختبار البعدي، وهذا ما تم اثباته احصائيًا وبذلك حقق الباحثان الفرض الذي كان بالاتجاه الصحيح. ويعزو الباحثان هذا التحسن في التفكير الايجابي وخفض مستوى التفكير السلبي المى أن هذه التمرينات قد حسَّنت من شعورهم الداخلي وطاقتهم الاييابية نحو التفاؤل نتيجة تخلصهم من الخمول من خلال تمرينات جعت بين القوة والمرونة وحركات التنفس، وبذلك اصبح الجمسم ضمن عملية الاسترخاء البدني والعقلي بعد اداء التمرينات، وكما يذكر الاستاذ حامد سليمان أن هذه الحالة تساعد على "خفض التوتر العضلي وبالتالي يسهم في خفض التوتر العقلي، إذ أن مجرد التركيز على الاسترخاء يعزل الدماغ المؤثرات الاخرى ويكون التركيز على العضلات وبالتالي سيكون هناك استرخاء عقلي و التفكير بالاتجاه الصحيح"(7). وعلى الرغم من ذلك فأن التعامل الحذر مع افراد عينة البحث من قبل الباحثين في اختيار التمرينات المناسبة للعينة وبكونهم مبتدئين في تطبيق تمرينات اليوغا قد اسهم في منحهم الشعور بالاطمئنان وهم تحت الحجر المنزلي والضغوطات التي يتعرضون لها وتفاعلهم مع الاداء من خلال بحث تجريبي يتم من خلال وسائل الاتصال الإلكترونية.

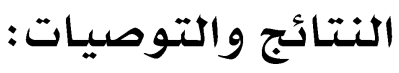

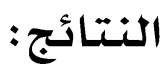
تطبيق تمرينات اليوغا اثناء الحجر المنزلي اثبت تأثيره الواضح على خفض التفكير السلبي ورفع مستوى التفكير الايجابي لدى افراد عينة البحث.

\section{التوصيات:}

- م - مارسة تمرينات اليوغا اثناء الحجر المنزلي لما لما من تأثير ايجابي على التفكير السلبي والايجابي. - الاهتمام بالتعليم الإلكتروني وحث الطلاب على رفع مستو اهم ومو اكبة التطور التكنلوجي. 
- اجراء دراسات وإعداد برامج من قبل خلية الأزمة لمواجهة جائحة كورونا للتخفيف من الضغوط
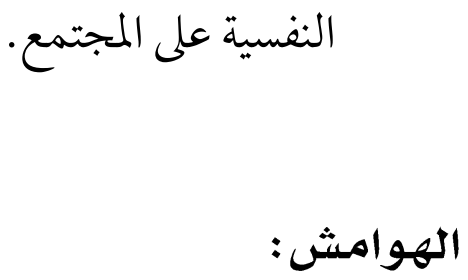

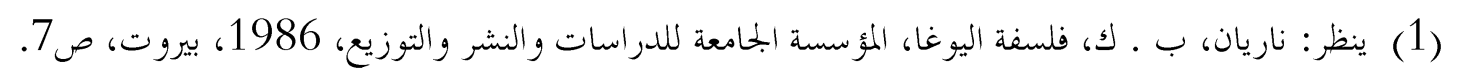

Hannah Nichols " Available at: https://www.news-medical.net/,p.4-29, (Accessed May, 1, : 2) (2)

$$
\text { 2020). }
$$

S Esthart Ekhart, "8 tips on how to do yoga at home- practice and all is coming ". Available at: : ينظر (3) https://www.ekhartyoga.com/ , p. 3-11, (Accessed May, 1, 2020)

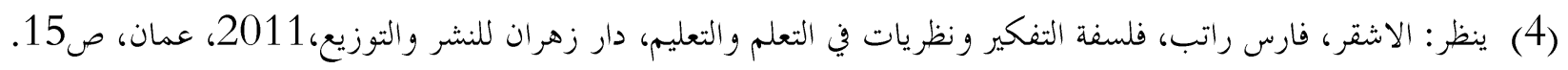

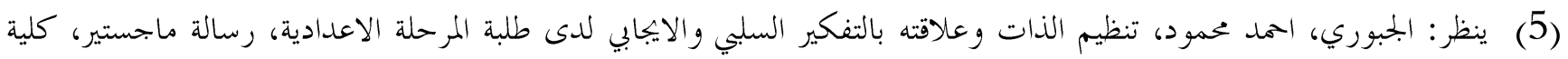

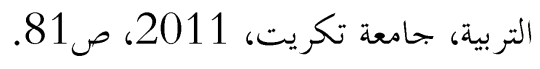

(6) ينظر: ياسين، وديع والعبيدي، حسن محمد، التطبيقات الاحصائية في بحوث التربية الرياضية، دار الكتب للطباعة والنشر، 1999،

$$
\text { الموصل، ص296. }
$$

(7) ينظر: الدليمي، حامد سليمان حمد، علم النفس الرياضي، ط1، دار العراب ودار نور للدراسات والنشر والترجمة، 2012، دمشق،

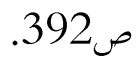

